\title{
Analisis Fungsi Implikasi Max-Min dan Max-Prod Dalam Pengambilan Keputusan
}

\author{
Raheliya Br Ginting \\ STT Poliprofesi Meda \\ E-mail: itink_ribu@yahoo.com
}

\begin{abstract}
Abstrak
Pengambilan keputusan harus dilakukan berdasarkan pertimbangan-pertimbangan tertentu agar keputusan yang diambil dapat bersifat objektif, karena pengambilan keputusan yang dilakukan tanpa pertimbangan yang benar dapat mengakibatkan keputusan yang diambil menjadi kurang objektif. Logika fuzzy merupakan salah satu metode untuk melakukan analisis sistem yang mengandung ketidakpastian. Pada penelitian ini digunakan metode mamdani dengan fungsi implikasi Min dan Prod dan defuzzifikasi dilakukan dengan menggunakan metode centroid. Dari analisis yang telah dilakukan maka didapatkan output dengan fungsi implikasi Max-Prod lebih besar dibanding Max-Min, maka sebelum menyelesaikan suatu kasus seharusnya dilakukan pertimbangan terhadap pemilihan fungsi implikasi yang sesuai..
\end{abstract}

Kata Kunci - Pengambilan Keputusan, Mamdani, Fungsi Implikasi, Max-Min, Max-Prod

Abstract

Decision-making should be performed based on the certain considerations in order to obtain objective decisions since the decision made without proper consideration can lead to less objective. Fuzzy logic is one of the methods for analyzing systems that contain uncertainty. In this reserch, we use implication functions Min and Prod in Mamdani method and defuzzifikasi performed by using the centroid method. From the earlier analysis done, we obtained the final results of Max-Min and Max-Prod where the Max-Prod implication functions manually produces the greater value than Max-Min, then before completing a case consideration should be done to the selection of an appropriate implication function.

Keywords - Decision Making, Mamdani, Implication Function

\section{PENDAHULUAN}

Setiap orang sering dihadapkan pada suatu keadaan dimana ia harus membuat suatu keputusan untuk memilih satu dari beberapa pilihan yang ada. Dalam membuat keputusan dan menentukan pilihan mana yang menjadi terbaik diperlukan data dan informasi. Namun data dan informasi yang diperlukan sulit untuk diukur nilai kepastiannya. Keputusan adalah pemilihan di antara berbagai alternatif [1]. Definisi ini mengandung tiga pengertian, yaitu: 1) ada pilihan atas dasar logika atau pertimbangan, 2) ada beberapa alternatif yang harus dipilih salah satu yang terbaik dan 3) ada tujuan yang ingin dicapai dan keputusan itu makin mendekatkan pada tujuan tersebut.

Pengambilan keputusan sebaiknya dilakukan berdasarkan pertimbangan-pertimbangan tertentu agar keputusan yang diambil dapat bersifat objektif, karena pengambilan keputusan yang dilakukan tanpa pertimbangan yang benar dapat mengakibatkan keputusan yang diambil menjadi kurang objektif. Pengambilan keputusan dalam teknik fuzzy dilakukan dalam beberapa tahap yaitu: fuzzification, penentuan membership function, rule evaluation dan defuzzification. Pada rule evaluation akan dilakukan pencarian fuzzy output dari fuzzy input dengan proses 
dimana suatu nilai fuzzy input yang berasal dari proses fuzzification kemudian dimasukkan kedalam sebuah rule yang telah dibuat untuk dijadikan sebuah fuzzy output. Rule evaluation merupakan bagian utama dari fuzzy karena rule evaluation akan menjadi dasar untuk menentukan sistem menjadi pintar atau tidak. Rule yang sudah ditentukan kemudian diaplikasikan kedalam fungsi implikasi. Secara umum ada 2 fungsi implikasi yaitu: Max-Min dan Max-Prod, fungsi implikasi yang sering digunakan dalam pengambilan keputusan adalah Max-Min[2]. Pemilihan metode implikasi fuzzy adalah masalah yang signifikan dalam pengembangan teori himpunan fuzzy[3]. Fungsi implikasi Max-Min dan Max-Prod merupakan metode yang paling umum digunakan karena mudah diimplementasikan dan bila diagregasikan dengan fungsi lain akan menghasilkan bentuk yang mudah di-defuzzification.

Berdasarkan uraian diatas maka pada penelitian ini penulis akan menganalisis pada bagian rule evaluation dengan fungsi implikasi metode Max-Min dan Max-Prod dan diterapkan pada fuzzy inferensi sistem Mamdani untuk mendapatkan keputusan yang lebih objektif. Pada penelitian [4] digunakan penerapan teknik fuzzy dalam menentukan keputusan untuk manajemen kanker dan fungsi implikasi yang digunakan adalah Max-Min. Pada penelitian [5] dilakukan pertimbangan alternatif pendekatan berdasarkan logika fuzzy mamdani untuk mengevaluasi permintaan energi yang berkaitan dengan industri dengan fungsi implikasi MaxMin. Pada penelitian [6] Menerapkan teori fuzzy untuk mengambil keputusan dalam pengembangan suatu produk baru. Dengan fungsi implikasi Max-Min dan pada penelitian[7] juga dilakukan penerapan himpunan fuzzy untuk sistem pendukung keputusan pemillihan Telephone Cellular.

Dari penelitian diatas dapat dilihat bahwa logika fuzzy banyak digunakan dalam pengambilan keputusan, diantaranya keputusan diambil dengan menganalisis fungsi keanggotaan. Dan pada penelitian ini penulis juga akan menggunakan logika fuzzy dalam pengambilan suatu keputusan dengan menganalisis pada fungsi implikasi metode Max-Min dan Max-Prod dengan menggunakan metode inferensi fuzzy Mamdani.

\section{METODE PENELITIAN}

. Metode Penelitian dilakukan dengan beberapa tahap, yang diharapkan dapat menggambarkan langkah penyelesaian suatu masalah yang ada pada penelitian ini. Adapun tahap-tahap yang dilakukan pada penelitian ini adalah:

1. Identifikasi Masalah

Pada tahap ini yang dilakukan adalah menentukan masalah yang akan digunakan untuk menguji metode Mamdani dengan fungsi implikasi metode Max-Min dan metode Max-prod

2. Data

Pada tahap ini yang dilakukan adalah menentukan data yang akan digunakan untuk menguji metode Mamdani dengan fungsi implikasi metode Max-Min dan metode Max-prod

3. Fuzzification

Pada fuzzification akan dilakukan tahapan penentuan derajat keanggotaan contoh variabel: Permintaan, Persediaan dan Produksi, kemudian variabel tersebut dibentuk kedalam himpunan sebagai contoh Permintaan dimasukan kedalam himpunan fuzzy: SEDIKIT dan BANYAK.

4. Membership Function

Selanjutnya himpunan yang telah terbentuk akan dimodelkan kedalam fungsi keanggotaan dan nilai keanggotaan berdasarkan himpunan input dan output.

5. Rule evaluation

Pada tahap ini akan dilakukan pencarian nilai fuzzy output dari fuzzy input dengan cara: suatu nilai fuzzy input yang berasal dari proses fuzzification kemudian dimasukkan kedalam sebuah rule yang telah dibuat untuk dijadikan sebuah fuzzy output. 
Fungsi yang digunakan yaitu:

a. Fungsi implikasi Max-Min, Fungsi ini akan memotong output himpunan fuzzy

b. Fungsi implikasi max-prod, Fungsi ini akan menskala output himpunan fuzzy

6. Defuzzification

Pada tahap defuzzification akan dilakukan pengambilan fuzzy output yang didapat dari rule evaluation kemudian dimasukkan ke dalam suatu membership function output. Kemudian nilai-nilai yang didapatkan dimasukkan ke dalam suatu rumus yang digunakan yaitu COG untuk mendapatkan hasil dalam bentuk crisp yang akan digunakan untuk pengambilan keputusan.

\subsection{Fungsi Implikasi Max-Min}

Fungsi implikasi merupakan struktur logika yang terdiri atas kumpulan premis dan satu konklusi. Bentuk dari Fungsi Implikasi adalah

IF $($ premis-1) $\bullet($ premis-2) $\bullet($ premis-3) $\bullet . . . . . ・($ premis-n) THEN Konklusi

dengan • adalah operator (AND atau OR).

Gambaran dari Fungsi Implikasi Max-Min dapat dilihat pada Gambar 1.

Rule I

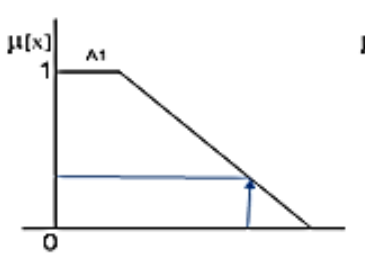

Var-1

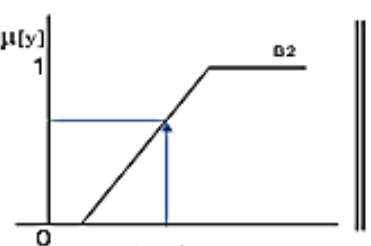

Var-2

Kumpulan Premis

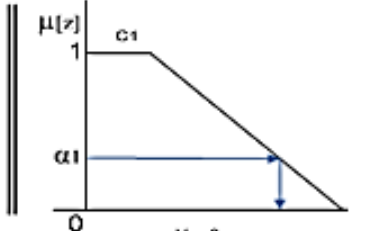

Var- 3

Konklusi

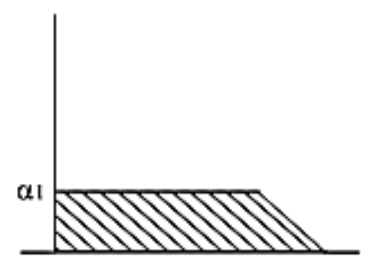

Daerah Output

Gambar 1. Penentuan daerah output pada Rule I dengan menggunakan Fungsi Min

Rule II

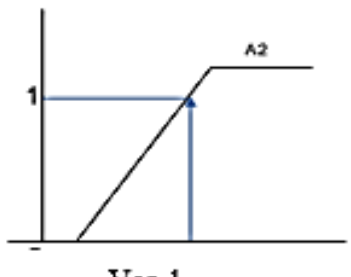

Var-1

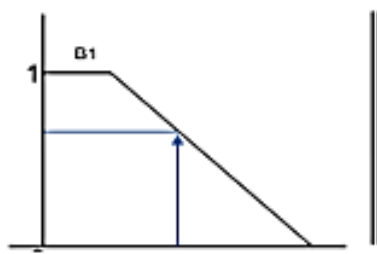

Var-2

Kumpulan Premis

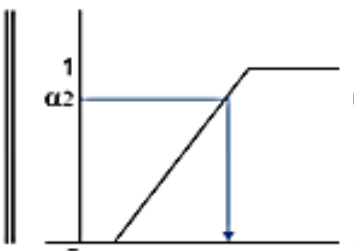

Var-3

Konklusi

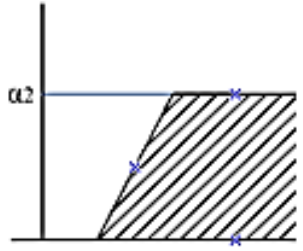

Daerah Output

Gambar 2. Penentuan daerah output pada Rule II dengan menggunakan Fungsi Min 
Citec Journal, Vol. 1, No. 2, Februari 2014 - April 2014

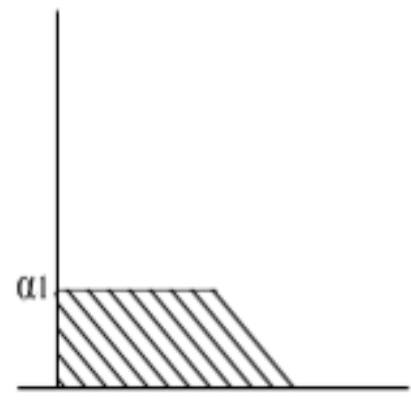

Daerah Output Rule I

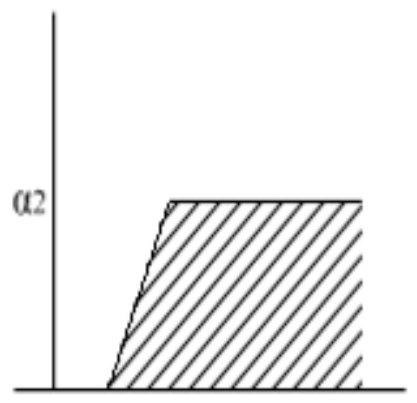

Daerah Output Rule II

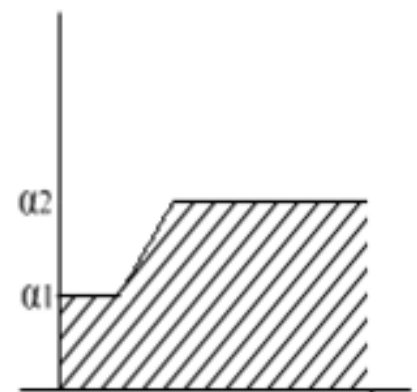

Daerah Output Gabungan Semua Rule

Gambar 3. Penentuan daerah output hasil dari Gabungan Rule dengan menggunakan Fungsi Max

\subsection{Fungsi Implikasi Max-Product}

Berbeda dengan penelitian sebelumnya [8] pada penelitian ini penulis melanjutkan dengan menganalisis fungsi implikasi Max-Prod. Pada Fungsi Implikasi Product (DOT), penghubung dari semua premis (operator) yang berupa AND atau OR tidak berpengaruh karena hasil nilai keanggotaan setiap premis akan dikalikan untuk menentukan $\square$ predikat dari rule.

Rule I
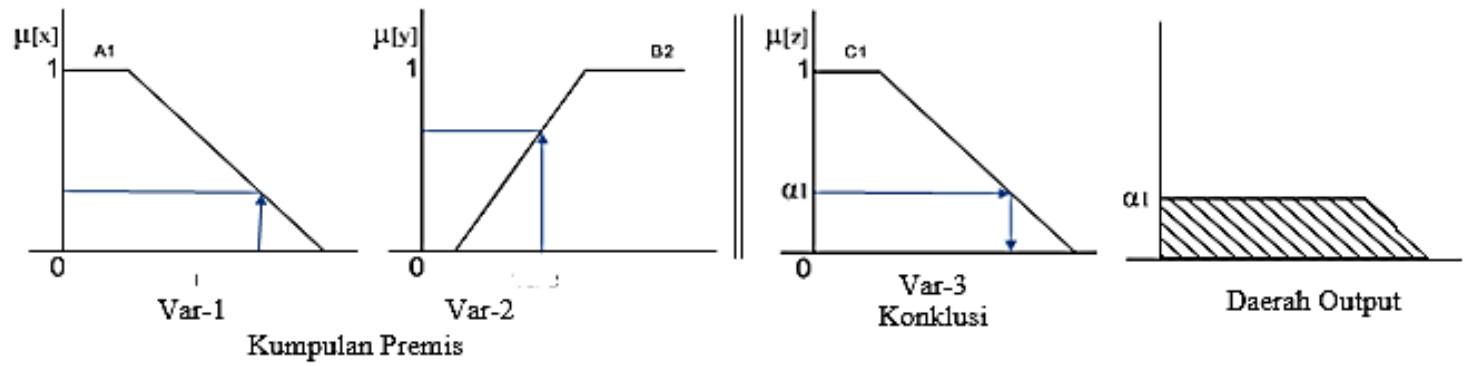

Gambar 4. Penentuan daerah output pada Rule I dengan menggunakan Fungsi Product

Rule II
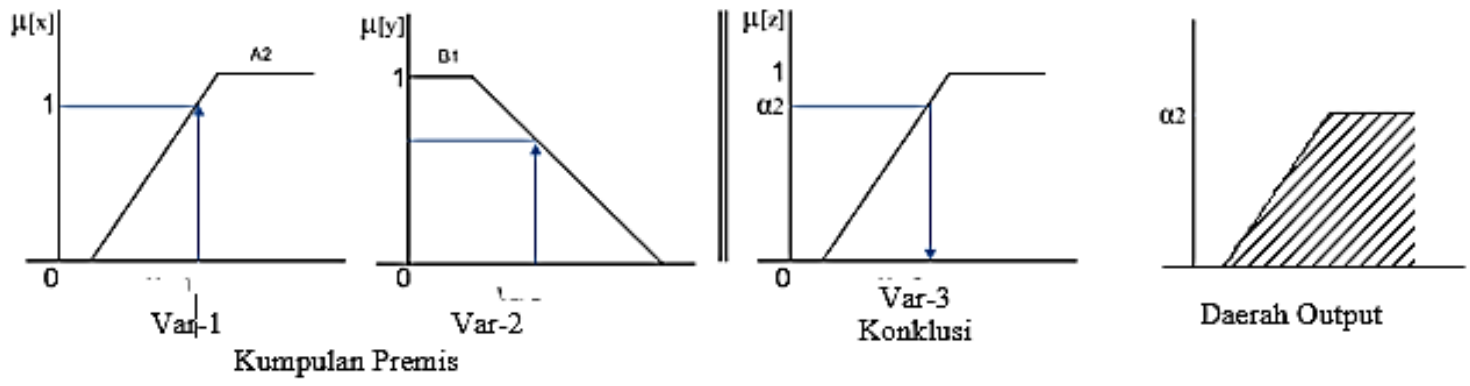

Gambar 5. Penentuan daerah output pada Rule II dengan menggunakan Fungsi Product 

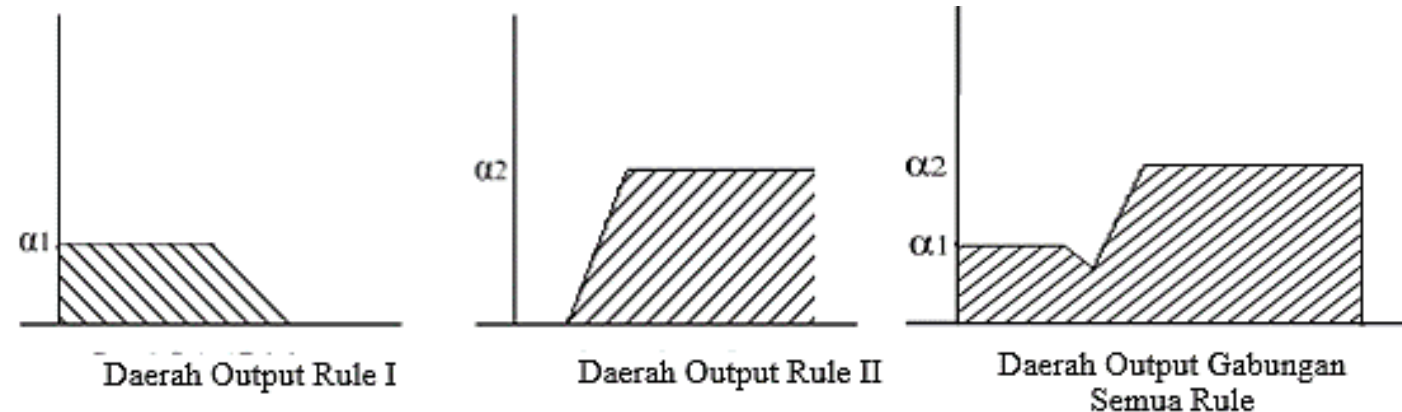

Gambar 6. Penentuan daerah output hasil dari gabungan rule dengan Fungsi Product

\section{HASIL DAN PEMBAHASAN}

Dalam menganalisis fungsi implikasi maka dibutuhkan suatu data. Pada penelitian ini penulis menggunakan data permintaan, persediaan dan produksi [8] yang kemudian digunakan untuk menganalisis fungsi implikasi Max-Min dan Max-Prod.

Tabel 1. Data Permintaan, Persediaan dan Jumlah Produksi

\begin{tabular}{|l|c|c|c|}
\hline Bulan & Permintaan (Unit) & Persediaan (Unit) & $\begin{array}{l}\text { Jumlah Produksi } \\
\text { (Unit) }\end{array}$ \\
\hline Juli 2004 & 19.319 & 2.706 & 20.046 \\
\hline Agustus 2004 & 19.745 & 1.204 & 22.054 \\
\hline September 2004 & 23.432 & 3.190 & 23.994 \\
\hline Oktpber 2004 & 15.145 & 2.334 & 15.394 \\
\hline November 2004 & 20.180 & 2.292 & 20.305 \\
\hline Desember 2004 & 14.868 & 2.224 & 14.105 \\
\hline Januari 2005 & 18.595 & 1.170 & 19.813 \\
\hline Pebruari 2005 & 19.514 & 1.664 & 19.808 \\
\hline Maret 2005 & 15.395 & 1.458 & 15.706 \\
\hline April 2005 & 22.378 & 1.658 & 23.404 \\
\hline Mei 2005 & 18.960 & 2.589 & 18.236 \\
\hline Juni 2005 & 21.641 & 1.186 & 22.749 \\
\hline
\end{tabular}

Sumber : PT. Sici Multi IndoMarmer

Dari tabel 1 dengan data 1 tahun, permintaan terbesar mencapai 23.432 unit/bulan dan permintaan terkecil mencapai 14.868 unit /bulan. Persediaan barang digudang terbanyak mencapai 3.190 unit unit /bulan dan terkecil pernah mencapai 1.179 unit/bulan. Dengan segala keterbatasannya, sampai juni 2005 perusahaan baru mampu memproduksi barang maksimum 23.994 unit/bulan dan minimum 14.105 unit/bulan, berapa jumlah produksi jika jumlah permintaan sebanyak 21945 unit dan persediaan digudang masih 1824 kemasan, apabila proses produksi perusahaan tersebut menggunakan 4 aturan fuzzy yaitu:

[R1] IF Permintaan TURUN And Persediaan BANYAK THEN Produksi Barang BERKURANG

[R2] IF Permintaan TURUN And Persediaan SEDIKIT THEN Produksi Barang BERKURANG

[R3] IF Permintaan NAIK And Persediaan BANYAK THEN Produksi Barang BERTAMBAH

[R4] IF Permintaan NAIK AND Persediaan SEDIKIT THEN Produksi Barang BERTAMBAH 
Langkah awal yang digunakan untuk menganalisa yaitu Menentukan variabel-variabel fuzzy dari kasus untuk menjadi model.

Pada kasus diatas terdapat 3 variabel untuk model fuzzy yaitu:

a. Variabel Permintaan

Variabel ini memiliki 2 himpunan fuzzy yaitu: NAIK dan TURUN.

b. Variabel Persediaan

Variabel ini memiliki 2 himpunan fuzzy yaitu: BANYAK dan SEDIKIT.

c. Variabel Produksi Barang

Variabel ini memiliki 2 himpunan fuzzy yaitu: BERTAMBAH dan BERKURANG.

Setelah menentukan variable maka langkah selanjutnya membentuk fungsi keanggotaan, pada penelitian ini fungsi keanggotaan yang digunakan adalah metode linear naik dan linear turun, implikasi yang digunakan Min dan Prod, sedangkan defuzifikasinya adalah centroid.

Menentukan fungsi keanggotaan dari setiap himpunan pada variabel-variabel model fuzzy. Variabel Permintaan untuk himpunan NAIK memiliki fungsi keanggotaan.

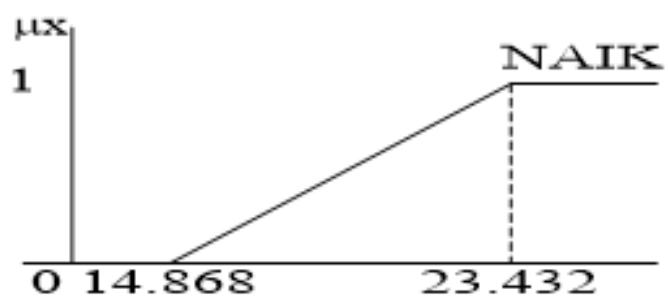

$$
\mu \text { PermintaanNAIK }=\left\{\begin{array}{cr}
0 & x \leq 14.868 \\
\frac{x-14.868}{8.564}, & 14.868 \leq 23.432 \\
1 & x \geq 23.432
\end{array}\right.
$$

Gambar 7. Fungsi Keanggotaan untuk Himpunan NAIK pada Variabel Permintaan dengan implikasi min

Selanjutrnya menentukan nilai variabel-variabel yang merupakan kategori sebagai premis pada Implikasi dari rule-rule yang ada. Dalam hal ini menentukan nilai variabel Permintaan (x), Persediaan (y) agar dapat dihitung berapa nilai dari variabel Produksi Barang $(\mathrm{z}), \mathrm{x}=21945, \mathrm{y}=1824$. Kemudian Mencari nilai dari Permintaan $(\mathrm{x})=21945$ sesuai dengan semua fungsi keanggotaan untuk masing-masing himpunan (NAIK dan TURUN).

$$
\begin{array}{lll}
\text { HPermintaanNAIK [21945] } & =(21945-14868) / 8564 & =0,826366 \\
\mu \text { PermintaanTURUN [21945] } & =(23432-21945) / 8564 & =0,173634
\end{array}
$$

Mencari nilai dari Persediaan $=1824$ sesuai dengan semua fungsi keanggotaan untuk masing-masing himpunan (SEDIKIT dan BANYAK).

$$
\begin{aligned}
& \text { HPersediaanSEDIKIT [1824] }=(3190-1824) / 2020=0,676238 \\
& \text { HPersediaanBANYAK [1824] }=(1824-1170) / 2020=0,323762
\end{aligned}
$$

Menerapkan Metode Max-Min dan Max-Prod untuk menentukan jumlah produksi barang. Semua metode tersebut akan diterapkan dengan Mamdani. 
Berikutnya adalah Mencari nilai $\alpha$ predikat dari setiap rule yang ada untuk mencari nilai $\mathrm{z}$ nya dengan metode MAX-MIN.

[R1] IF Permintaan TURUN And Persediaan BANYAK THEN Produksi Barang BERKURANG

$$
\begin{aligned}
\alpha \text {-predikat } 1 & =\mu \text { PermintaanTURUN } \cap \mu \text { PersediaanBANYAK } \\
& =(\mu \text { PermintaanTURUN [21945], } \quad \mu \text { Persediaan BANYAK [1824] }) \\
& =\min (0,17 ; 0,32) \\
& =0,17
\end{aligned}
$$
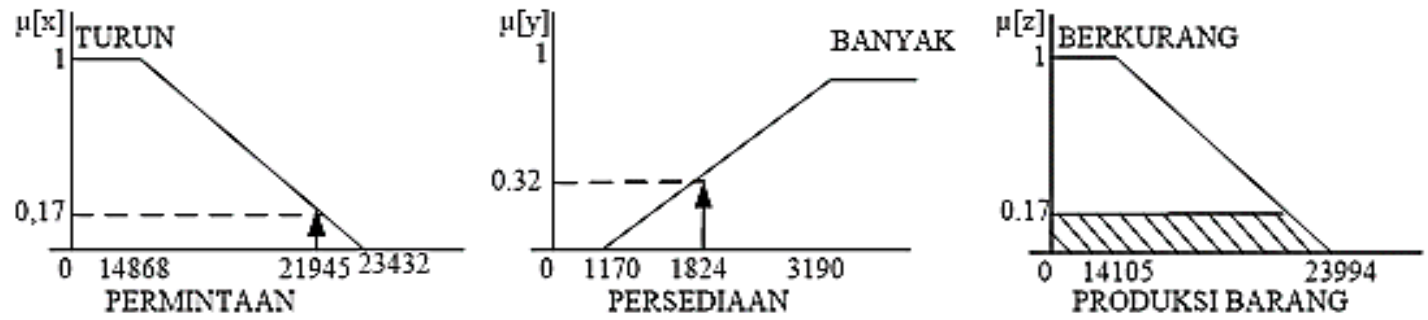

Gambar 8. Penerapan Rule R1 pada Fungsi Max-Min dengan Metode Mamdani

Berikutnya adalah Mencari nilai $\alpha$ predikat dari setiap rule yang ada untuk mencari nilai z nya dengan metode MAX-PROD.

[R1] IF Permintaan TURUN And Persediaan BANYAK THEN Produksi Barang BERKURANG
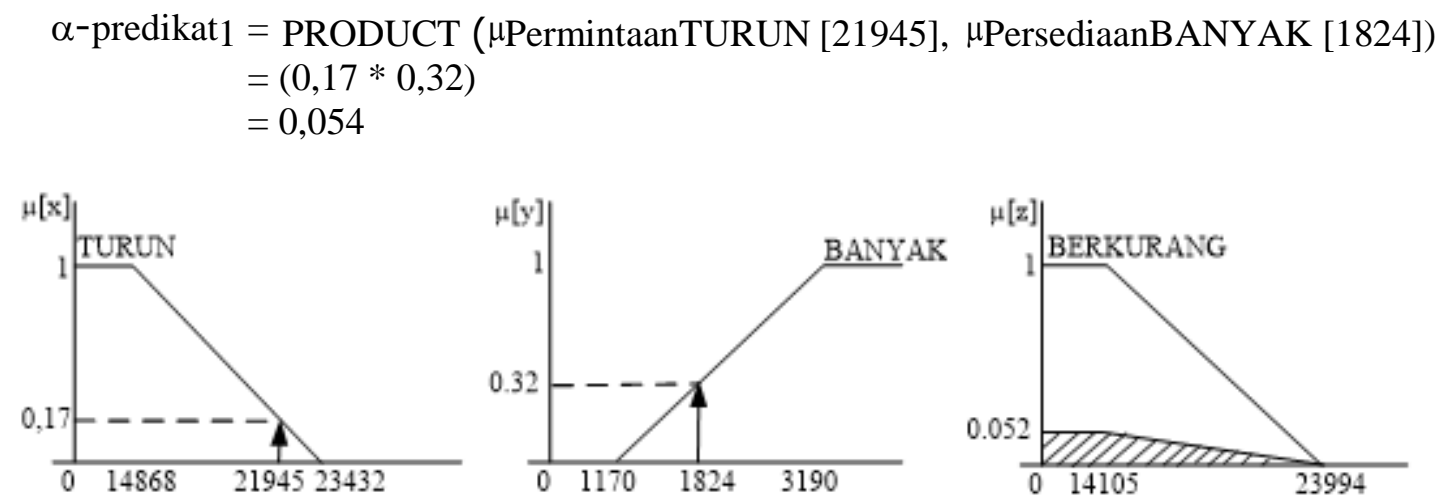

Gambar 9. Penerapan Rule R1 pada Fungsi Max-Prod dengan Metode Mamdani

Langkah berikutnya menerapkan komposisi aturan Max pada semua aturan.Max merupakan proses menggabungkan seluruh hasil dari daerah R1, R2, R3 dan R4. Sehingga diperoleh luas daerah dari komposisi seluruh aturan seperti gambar berikut.

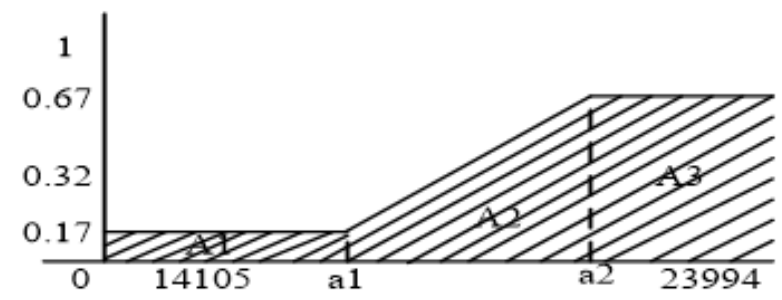

Gambar 10. Hasil Gabungan dari Output seluruh Rule dengan implikasi Min 
Citec Journal, Vol. 1, No. 2, Februari 2014 - April 2014

Menentukan nilai dari batasan yaitu $\mathrm{a}_{1}$ dan $\mathrm{a}_{2}$.

Berdasarkan hasil grafik komposisi aturan Max, bentuk grafik cenderung ke bentuk PRODUKSI BARANG BERTAMBAH, maka diperoleh:

$$
\begin{aligned}
& \left(a_{1}-14105\right) / 9889=0,17 \rightarrow a_{1}=15786.13 \\
& \left(a_{2}-14105\right) / 9889=0,67 \rightarrow a_{2}=20730.63
\end{aligned}
$$

Dengan demikian fungsi keanggotaan untuk hasil komposisi ini adalah

$$
\mu[z]=\left\{\begin{array}{cr}
0.17 & z \leq 15786.13 \\
\frac{z-14105}{9889}, & 15786.13 \leq 20730.63 \\
0.67 & z \geq 20730.63
\end{array}\right.
$$

Menerapkan komposisi aturan Max pada semua aturan dengan implikasi PRODUCT Diperoleh:
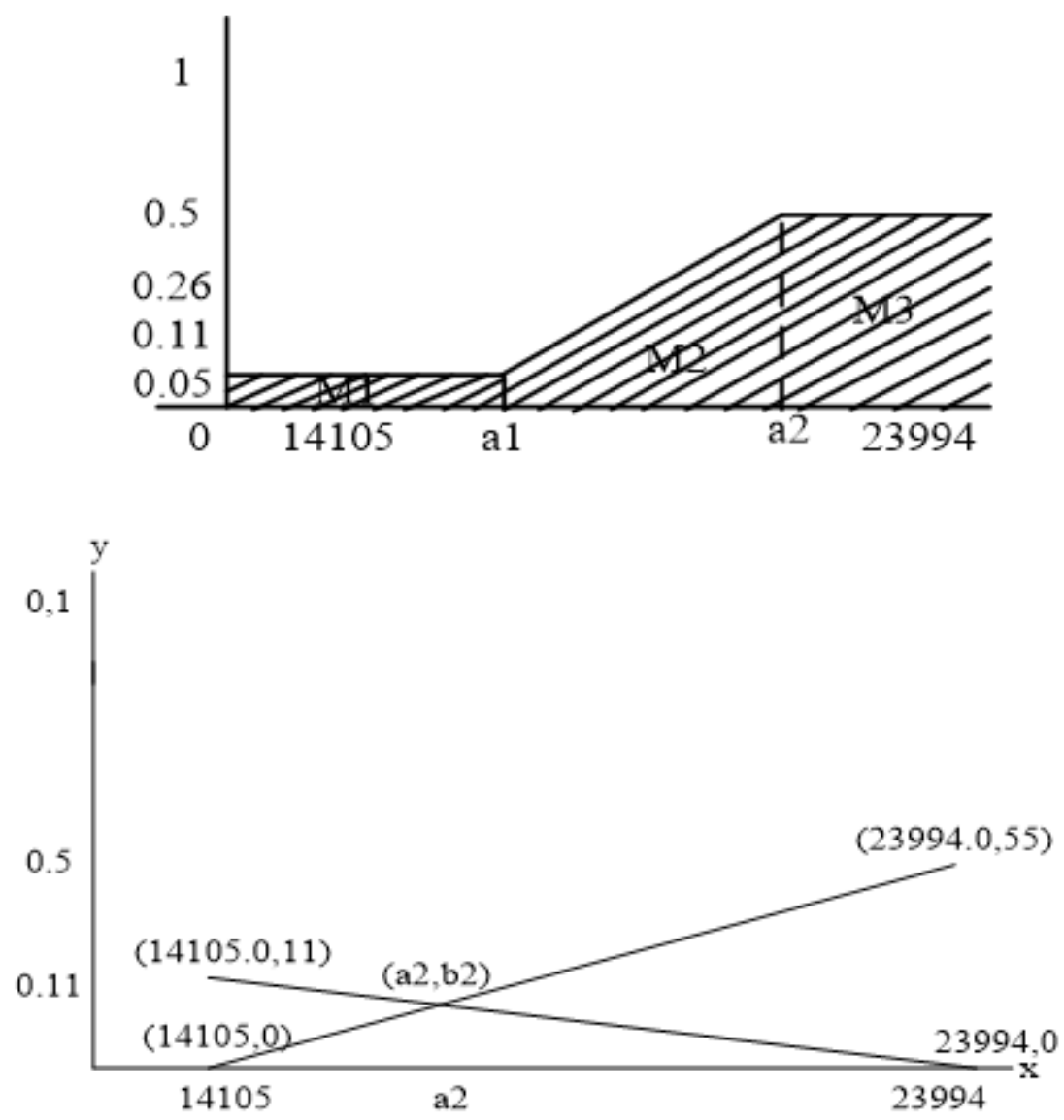

Gambar 11. Perpotongan Fungsi Produksi Barang Bertambah dan Fungsi Produksi Barang Berkurang (Dengan implikasi Product) 
Langkah akhir adalah Penegasan (Defuzzy) Metode penegasan yang akan digunakan adalah metode centroid. Pada tahap ini akan didapat hasil yang dikerjakan secara manual dan yang di uji dengan menggunakan MATLAB. Hasil yang didapat secara manual dengan fungsi implikasi MAX-MIN dalam Metode Mamdani dapat dilihat pada gambar berikut:

$Z=\frac{21182162+35415749.25+48894260}{298.14+2112.037+2165.100}=23056.99$

Kesimpulan: Jumlah yang harus diproduksi sebanyak 23056.99 kemasan.

Hasil yang didapat secara manual dengan fungsi implikasi MAX-PROD dalam Metode Mamdani dapat dilihat pada gambar berikut:

Titik pusat diperoleh dari

$$
\begin{aligned}
\mathrm{Z} & =\frac{11680187,77+11889890+55250889,98}{201.61+177+3076} \\
& =\frac{78820968}{3454}
\end{aligned}
$$

Setelah penulis melakukan analisis masalah dengan cara manual, maka tahap berikutnya penulis melakukan pengujian dengan menggunakan MATLAB. Hasil yang didapat dengan mengunakan MATLAB dapat dilihat pada gambar 11.

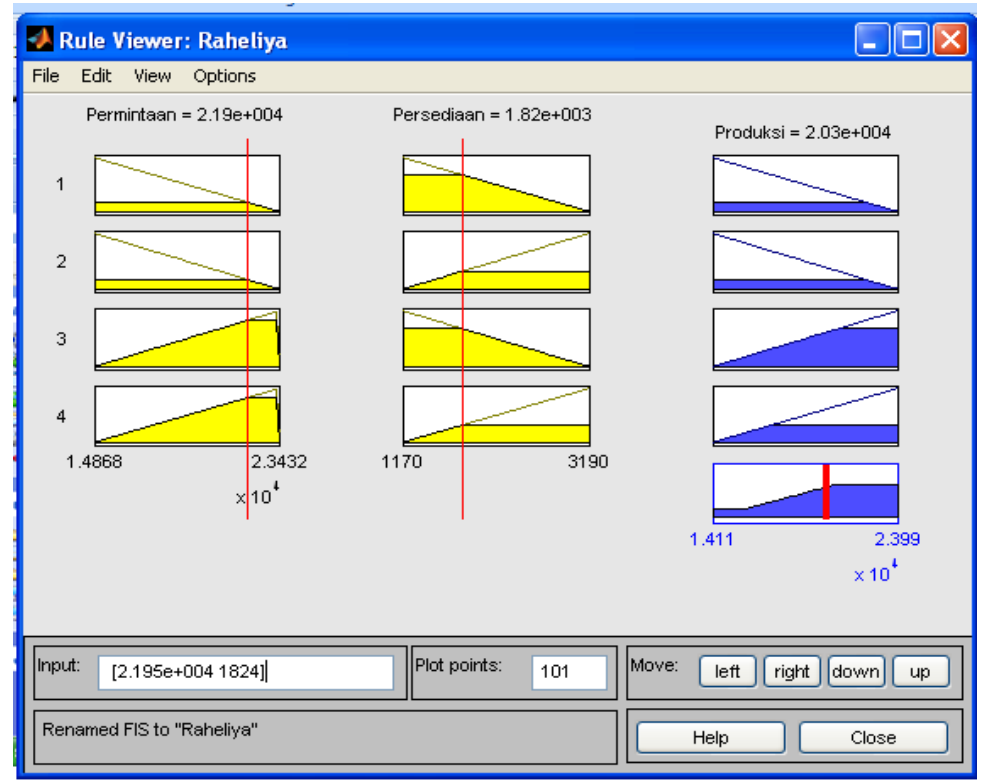

Gambar 11. Hasil Output untuk Fungsi Implikasi Min 


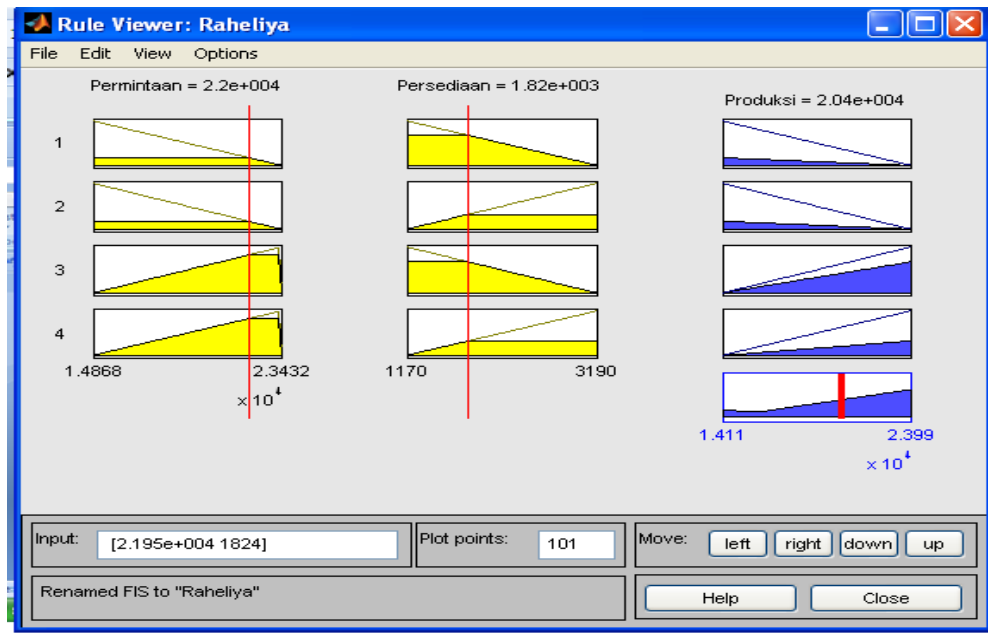

Gambar 12. Hasil Output untuk Fungsi Implikasi Max-Prod

\section{KESIMPULAN}

Berdasarkan hasil penelitian yang telah dilakukan, serta uraian - uraian yang telah dikemukakan, maka dapat diambil kesimpulan yaitu:

1. Dengan melakukan analisis terlebih dahulu terhada metode yang digunakan maka akan didapatkan keputusan yang lebih objektif.

2. Dalam penyelesaian kasus yang dilakukan penulis maka penggunana Fungsi implikasi metode Max-Min lebih mudah dalam mendapatkan output dibanding metode Max-Prod.

3. Hasil luas dari setiap rule baik dari fungsi Max-Min maupun dengan Max-Prod akan digabungkan dengan konsep max (union). Sehingga dengan demikian pemilihan dari fungsi implikasi Max-Min dan Max-Prod akan berpengaruh untuk menentukan luas daerah variabel output serta titik pusat dari daerah tersebut

\section{SARAN}

Dari analisis yang telah dilakukan penulis terhadap metode Max-Min dan Max-Prod, maka penulis akan memberikan saran yang diharapkan dapat bermanfaat, adapun saran-saran dari penulis yaitu:

1. Dari analisis yang dilakukan penulis terhadap suatu kasus maka Fungsi implikasi Max-Min dan Max-Prod yang diterapkan dengan menggunakan metode mamdani memilik hasil yang berbeda dengan hasil pengujian MATLAB, oleh karena itu dapat dilakukan pengujian lebih lanjut.

2. Penelitian ini dapat dikembangkan lagi dengan menganalisis fuzzy metode inferensi fuzzy Tsukamoto dan juga Sugeno dengan fungsi implikasi Max-Min dan juga Max-Prod atau dengan fungsi implikasi lainnya seperti implikasi zadeh, lukasiewicz, Goedel, Goguen

3. Untuk pengembangan berikutnya metode mamdani dengan fungsi implikasi metode MaxMin dan Max-Prod dapat diuji dengan beberapa kasus untuk mendapatkan hasil yang lebih baik lagi 


\section{DAFTAR PUSTAKA}

[1] Stoner J. A. F., Freeman, R. E., Gilbert Jr, D. R., 1996, Management Jilid II, PT. Prenhallindo, Jakarta.

[2] Kusumadewi, Purnomo, S., 2004, Aplikasi Logika Fuzzy untuk Pendukung Keputusan, Graha Ilmu, Yogyakarta.

[3] Zhu, H., Yang, 2007, Fuzzy Systems and Knowledge Discovery, International Conference, Vol 4, hal 154-158.

[4] Abou A. E., Barakat, Ebrahim, S., Awad, 2011, A Fuzzy Decision Support System for Management of Breast Cancer, International Journal Of Advanced Computer Science and Application, Vol 2, No 3, hal 35.

[5] Musee, N., Lorenzen, L., Aldrich, C., 2006, Decision Support For Evaluating Energy Demand in Vinification Processes Using Fuzzy Sets Theory, Journal of Energy in Southern Africa, Vol 17, No 4, hal 4-18.

[6] Wulandari, F., 2005, Pembuatan Sistem Pendukung Keputusan Berbasis Teori Fuzzy untuk mengembangkan suatu Produk Baru, Jurnal Sains, Vol 2, No 2, hal 62.

[7] Hamdani. 2011, Penerapan Himpunan Fuzzy Untuk Sistem Pendukung Keputusan Pemilihan Telephone Cellular, Jurnal Informatika Mulawarman, Vol 6, No 1, hal 40-66.

[8] Djunaidi, M, Eko S, Fajar W. A., 2005, Penentuan Jumlah Produksi dengan Aplikasi Metode Fuzzy, Journal Ilmiah Teknik Industri, Vol 4, No. 2, hal 95-104. 